\title{
Autofluorescence multiphoton microscopy for visualization of tissue morphology and cellular dynamics in murine and human airways
}

\author{
Sarah Kretschmer ${ }^{1,8}$, Mario Pieper ${ }^{1,2,8}$, Gereon Hüttmann ${ }^{2,3}$, Torsten Bölke ${ }^{4}$, Barbara Wollenberg ${ }^{5}$, Leigh M Marsh ${ }^{6}$, \\ Holger Garn ${ }^{7}$ and Peter König ${ }^{1,2}$
}

The basic understanding of inflammatory airway diseases greatly benefits from imaging the cellular dynamics of immune cells. Current imaging approaches focus on labeling specific cells to follow their dynamics but fail to visualize the surrounding tissue. To overcome this problem, we evaluated autofluorescence multiphoton microscopy for following the motion and interaction of cells in the airways in the context of tissue morphology. Freshly isolated murine tracheae from healthy mice and mice with experimental allergic airway inflammation were examined by autofluorescence multiphoton microscopy. In addition, fluorescently labeled ovalbumin and fluorophore-labeled antibodies were applied to visualize antigen uptake and to identify specific cell populations, respectively. The trachea in living mice was imaged to verify that the ex vivo preparation reflects the in vivo situation. Autofluorescence multiphoton microscopy was also tested to examine human tissue from patients in short-term tissue culture. Using autofluorescence, the epithelium, underlying cells, and fibers of the connective tissue, as well as blood vessels, were identified in isolated tracheae. Similar structures were visualized in living mice and in the human airway tissue. In explanted murine airways, mobile cells were localized within the tissue and we could follow their migration, interactions between individual cells, and their phagocytic activity. During allergic airway inflammation, increased number of eosinophil and neutrophil granulocytes were detected that moved within the connective tissue and immediately below the epithelium without damaging the epithelial cells or connective tissues. Contacts between granulocytes were transient lasting $3 \mathrm{~min}$ on average. Unexpectedly, prolonged interactions between granulocytes and antigen-uptaking cells were observed lasting for an average of $13 \mathrm{~min}$. Our results indicate that autofluorescence-based imaging can detect previously unknown immune cell interactions in the airways. The method also holds the potential to be used during diagnostic procedures in humans if integrated into a bronchoscope.

Laboratory Investigation (2016) 96, 918-931; doi:10.1038/labinvest.2016.69; published online 11 July 2016

Inflammatory airway diseases such as allergic asthma and chronic obstructive pulmonary disease are an increasing problem in human health. ${ }^{1}$ Despite intensive research, the underlying immunological processes are still not completely understood. ${ }^{2-4}$ A general problem in unraveling immunological mechanisms is that widely used powerful techniques, such as fluorescence-activated cell sorting or cytokine assays, give detailed information about the involved cell types and their phenotypes, but no information on time-resolved localization and activity of these cells. Histological techniques can give detailed information about the localization of cells at a single time point, but give no information on movement, time course of cell-cell interactions, and their morphological changes over time. In recent years, the use of multiphoton microscopy to follow the dynamics of inflammatory cells directly has greatly increased our understanding of immune processes. ${ }^{5,6}$

Most multiphoton microscopy studies to date use genetically engineered animals that express fluorescent proteins in cells of interest to detect and follow their fate in the tissue. Although very powerful, this approach has constraints. A suitable mouse strain is not always available and only labeled cells can be visualized. Information about the surrounding tissue is largely lacking. Furthermore, this approach of genetic labeling is not possible in human subjects.

${ }^{1}$ Center for Structural and Cell Biology in Medicine, Institute of Anatomy, University of Lübeck, Lübeck, Germany; ${ }^{2}$ Airway Research Center North, German Center for Lung Research (DZL), Lübeck, Germany; ${ }^{3}$ nstitute of Biomedical Optics, University of Lübeck, Lübeck, Germany; ${ }^{4}$ Institute of Anatomy II, University Hospital Jena, Jena, Germany; ${ }^{5}$ Clinic for Otolaryngology, University Clinic of Schleswig-Holstein, Campus Lübeck, Lübeck, Germany: ${ }^{6}$ Ludwig Boltzmann Institute for Lung Vascular Research, Graz, Austria and ${ }^{7}$ Institute for Laboratory Medicine and Pathobiochemistry, Member of the German Center for Lung Research (DZL), Philipps University of Marburg, Marburg, Germany Correspondence: Dr P König, MD, Center for Structural and Cell Biology in Medicine, Institute of Anatomy, University of Lübeck, Ratzeburger Allee 160, Lübeck 23562, Germany.

E-mail: koenig@anat.uni-luebeck.de

${ }^{8}$ The first two authors contributed equally to this work.

Received 14 September 2015; revised 19 May 2016; accepted 19 May 2016 
A rarely used advantage of multiphoton microscopy is the ability to image endogenous fluorophores, such as $\mathrm{NAD}(\mathrm{P}) \mathrm{H}$ or flavoproteins, ${ }^{7-11}$ and extracellular fibers by secondharmonic generation. ${ }^{12}$ Studies in the murine small intestine and the eye have shown that multiphoton imaging is able to visualize tissue morphology and cellular dynamics using only endogenous fluorophores. ${ }^{13-15}$ The use of autofluorescence is not confined to animals and this approach has already been used to visualize skin morphology in patients ${ }^{16}$ or to detect structural changes in lungs of idiopathic pulmonary arterial hypertension patients. ${ }^{17}$ Despite the potential usefulness of autofluorescence imaging in the airways, studies that show the feasibility of this approach to better understand airway inflammation are lacking.

The aim of this study was to demonstrate the usefulness of autofluorescence-based multiphoton microscopy for imaging the airways. We evaluated this technique in explanted mouse tracheae and in the trachea of living mice. To test if this imaging technique is suitable for human material, we also imaged explanted human airway tissue. Autofluorescence alone gave a detailed overview of the morphology and allowed to follow the dynamic behavior of individual cells in mice and humans without the need for genetic reporters. Using this approach, we have observed previously unknown dynamic interactions of antigen-uptaking cells with neutrophil and eosinophil granulocytes during airway inflammation. In combination with external dyes, this technique is a powerful tool to better understand immune mechanisms without the use of genetically engineered animals and holds the potential to be used as diagnostic tool in humans.

\section{MATERIALS AND METHODS}

\section{Animals}

For tracheal imaging, male $\mathrm{C} 57 \mathrm{BL} / 6$ or Balb/c mice aged 6-25 weeks were used (Charles River Laboratories, Sulzfeld, Germany). All animals were kept according to institutional guidelines with a $12 \mathrm{~h}$ day-night cycle and food and drink ad libitum. All animal experiments were approved by the Ministerium für Landwirtschaft, Umwelt und ländliche Räume des Landes Schleswig-Holstein, or the Regierungspräsidium Gießen. All measures were taken to keep animals suffering to a minimum.

\section{Human Nasal Concha Samples}

The use of human material was approved by the ethics committee of the Universität zu Lübeck (No. 04-158). Parts of nasal conchae of human subjects were removed during medically necessary turbinectomies and were then transferred to a Delta T4 Culture Dish (Bioptechs, Butler, PA). The bottom of the dish was covered with a thin film of Sylgard polymer (Dow Corning, Wiesbaden, Germany) to allow fixation of the tissue with insect needles and was filled with $2 \mathrm{ml}$ HEPES-buffered Ringer's solution. The temperature was held constant at $37^{\circ} \mathrm{C}$ during imaging.

\section{Model of Allergic Airway Inflammation}

For initiation of an acute allergic airway inflammation, 6-week-old female Balb/c mice $(n=13)$ were sensitized subcutaneously with $10 \mu \mathrm{g}$ obalbumin (OVA; OVA grade VI; Sigma, Hamburg, Germany) in $200 \mu \mathrm{l}$ PBS on days 0, 7, and 21 and were provoked with a nebulized 1\% OVA aerosol for $20 \mathrm{~min}$ on days 26, 27, and 28. Control animals were treated with PBS alone $(n=4)$. After the last provocation of the mice, multiphoton microscopy imaging was carried out on days 28,29 , or 30 .

\section{Preparation of the Trachea for the Ex Vivo Experiments} Mice were killed by inhalation of isoflurane (Baxter, Unterschleißheim, Germany). The thorax was opened and the submandibular gland and the infrahyoid musculature were removed. The trachea was cut caudal to the larynx and cranial to the bifurcation and transferred to a Delta T4 Culture Dish (Bioptechs, Boulder, PA). The bottom of the dish was covered with a thin film of Sylgard polymer (Dow Corning, Wiesbaden, Germany) to allow fixation of the tissue with insect needles and was filled with $2 \mathrm{ml}$ cooled HEPESbuffered Ringer's solution, $\mathrm{pH}$ 7.4. Connective tissue and blood vessels were removed.

For imaging the tracheal epithelium with a high resolution, the trachea was oriented with the trachealis muscle facing upward. For imaging the tracheal wall from the outside, the trachea was oriented with the tracheal muscle facing downward (Supplementary Figure 1a). To expose the epithelium, the tracheal muscle was cut (Supplementary Figure 1b). Before imaging, the HEPES-buffered Ringer's solution was replaced with fresh buffer and the culture dish was transferred to the Delta T Stage holder, which kept the sample at $37^{\circ} \mathrm{C}$ during the experiment (Supplementary Figure 1c).

\section{Ex Vivo Multiphoton Microscopy}

Imaging was carried out with a modified JenLab DermaInspect 101 multiphoton microscope (JenLab GmbH, Jena, Germany) equipped with a W-Plan-Apochromat x20 dip in objective (NA =1.0; Carl Zeiss Microscopy GmbH, Jena, Germany) and a tunable femtosecond titanium-sapphire laser (Mai Tai; Newport Spectra-Physics GmbH, Darmstadt, Germany). An excitation wavelength of $750 \mathrm{~nm}$ was chosen for imaging tissue autofluorescence as well as exogenous dyes. With an excitation wavelength of $800 \mathrm{~nm}$, the secondharmonic generation signal and autofluorescence of the collagen was detected. Emitted light was simultaneously detected in four spectral channels (channel 1: $380-450 \mathrm{~nm}$; channel 2: $450-500 \mathrm{~nm}$; channel 3: 500-580 nm; channel 4: $580-680 \mathrm{~nm}$ ) by photomultiplier tubes (Hamamatsu R1294A and R1295A; Hamamatsu Photonics Deutschland GmbH). The dichroic filters provide a separation between known fluorescence emission spectra of endogenous fluorophores (Supplementary Table 1$)$. Images $(512 \times 512$ pixels) were recorded in either 7.4 or $13.4 \mathrm{~s}$. Time series of a single focal 
plane, 3D stacks, or 3D stacks over time up to $1 \mathrm{~h}$ were recorded. In the 3D stacks, the images were taken every $2 \mu \mathrm{m}$. The stacks were processed with Imaris software (Bitplane, Zurich, Switzerland) and a denoizing procedure for autofluorescence multiphoton images. ${ }^{18}$

Lesions of small areas of the concha nasalis epithelium and the murine trachea were induced by focusing the Ti-sapphire femtosecond laser beam $(80 \mathrm{~mW})$ to single epithelial cells for 2-8 s.

\section{Video Microscopy of the Airway Epithelium}

To image the cilia-driven particle transport, the transmitted light modus of the microscope was used and movement of the particles was recorded using a Neo sCMOS camera (Andor, Belfast, UK). Images were recorded with 5 frames/s. Subsequently, the focal plane was shifted into the epithelium and multiphoton images were recorded.

\section{Exogenous Staining of Cells}

For fluorescence labeling, antibodies or dye-quenched ovalbumin (DQ OVA) were given either into the buffer solution for $1 \mathrm{~h}$ (antibodies) followed by a change of buffer or the sample was incubated during the whole experimental time with DQ OVA or propidium iodide (BD Biosciences, Heidelberg, Germany; $0.1 \mu \mathrm{g} / \mathrm{ml}$ ). The antibodies used were as follows: FITC-conjugated rat anti-CD90.2 antibody (clone 30-H12; Leinco Technologies, St Louis, MO, USA; $0.167 \mu \mathrm{g} / \mathrm{ml}$ ), FITC-conjugated rat anti-Ly6C/G (Gr-1) antibody (clone RB6-8C5; Invitrogen $\mathrm{GmbH}$, Karlsruhe, Germany; $0.25 \mu \mathrm{g} / \mathrm{ml}$ ), biotinylated mouse anti-CD31 (PECAM-1) antibody (clone Mec 13.3; BD Biosciences, Heidelberg, Germany; $1 \mu \mathrm{g} / \mathrm{ml}$ ), Alexa 488-conjugated streptavidin (Invitrogen $\mathrm{GmbH}$, Karlsruhe, Germany; $1.25 \mu \mathrm{g} / \mathrm{ml}$ ). The fluorescence-labeled allergen DQ OVA was used to stain antigen-uptaking cells (Invitrogen $\mathrm{GmbH}$, Karlsruhe, Germany; $50 \mu \mathrm{g} / \mathrm{ml})$.

\section{Quantification of Contacts Between Granulocytes and Antigen-Uptaking Cells}

The duration of contact between two granulocytes or a granulocyte and an antigen-uptaking cell labeled by uptake of DQ OVA was determined in recorded z-stacks. Direct contact between two cells was verified rotating the imaging stack using the Imaris 3D-rendering function. Statistical analysis was performed by using Mann-Whitney $U$-test. A P-value $<0.05$ was considered statistically significant.

\section{Fluorescence Immunohistochemistry for Confocal Microscopy}

Cryosections (10-12 $\mu \mathrm{m}$ thickness) from $4 \%$ paraformaldehyde-fixed and sucrose-cryoprotected murine tracheae were incubated with primary antibodies diluted in PBS ( $\mathrm{pH}$ 7.4) overnight.

For double labeling with FITC-conjugated rat anti-Ly6C/G (Gr-1) antibody and with rabbit anti-CCR3 antibody (clone
Y31; Biomol GmbH, Hamburg, Germany; $0.5 \mu \mathrm{g} / \mathrm{ml}$ ) or Alexa 647-conjugated rat anti-Ly6G antibody (clone 1A8; BioLegend Europe BV, Uithoorn, The Netherlands; $2.5 \mu \mathrm{g} / \mathrm{ml}$ ), sections were incubated with the antibodies overnight. For double labeling with the two conjugated antibodies, sections were rinsed in PBS and coverslipped using buffered Mowiol 4-88, pH 8.5 (Sigma-Aldrich, Munich, Germany) on the next day. For double labeling with the unconjugated antibody, sections were washed and then incubated with the fluorophore-conjugated secondary antibody donkey antirabbit IgG Alexa Fluor 555 (Invitrogen GmbH, Karlsruhe, Germany; $2.5 \mu \mathrm{g} / \mathrm{ml}$ ) to detect non-labeled anti-CCR3 antibody. After incubation for $1 \mathrm{~h}$, sections were rinsed in PBS and coverslipped.

For double labeling of DQ OVA with rat anti-MHC II antibody, tracheae with DQ OVA labeling during the multiphoton microscopy were fixed with $4 \%$ paraformaldehyde, rinsed with PBS, and then stained with anti-MHC II antibody (clone CD311; 1:5 diluted cell culture supernatant) in PBS overnight. Tracheae were rinsed and incubated with Alexa Fluor 555-conjugated donkey anti-rat IgG (Invitrogen $\mathrm{GmbH}$, Karlsruhe, Germany; $2.5 \mu \mathrm{g} / \mathrm{ml}$ ). After incubation for $1 \mathrm{~h}$, tracheae were rinsed in PBS and coverslipped. Sections and whole mounts were imaged by using a confocal laser scanning microscope (510 Meta; Carl Zeiss Microscopy GmbH, Jena, Germany).

\section{Intravital Imaging}

Mice were anesthetized by injecting $500 \mu \mathrm{l}$ of a solution with $9 \mu \mathrm{g} / \mathrm{ml}$ fentanyl (Bayer, Leverkusen Germany), $0.4 \mathrm{mg} / \mathrm{ml}$ midazolam (Curamed, Karlsruhe, Germany), and $50 \mu \mathrm{g} / \mathrm{ml}$ medetomidin (Pfizer, Karlsruhe, Germany) in $0.9 \% \mathrm{NaCl}$ intraperitoneally. The artificially ventilated mice (FlexiVent; SCIREQ, Montreal, QC, Canada) were placed on a heated microscope stage $\left(37^{\circ} \mathrm{C}\right)$. For optical access, the trachea was exposed by opening the skin over the trachea, displacing the submandibular glands, and removing the infrahyoid musculature. The trachea was held in place by two curved titanium wires and placed under the XLUMPLFL $\times 20$ W/0.95 objective (Olympus, Hamburg, Germany). Vidisic (Bausch+Lomb $\mathrm{GmbH}$, Berlin, Germany) was used as an immersion medium. Ventilation-triggered images were recorded using a TriM Scope Multiphoton Microscope (LaVision BioTec GmbH, Bielefeld, Germany) (Supplementary Figure 1d). Images were taken during $2 \mathrm{~s}$ pressure holds of the ventilator, which followed after a deep inflation maneuver using the DIEPH protocol. Fluorescence was excited at $740 \mathrm{~nm}$ and emitted light was detected in three spectral channels $(<495,495-560$ and $>560 \mathrm{~nm}$ ). Image processing was carried out using Imaris (Bitplane, Zurich, Switzerland) and a denoizing procedure for autofluorescence multiphoton images. ${ }^{18}$

\section{RESULTS}

As visualization of three-dimensional autofluorescent structures and cellular dynamics in figures can be difficult, the 


\section{Transmitted light microscopy cross section}

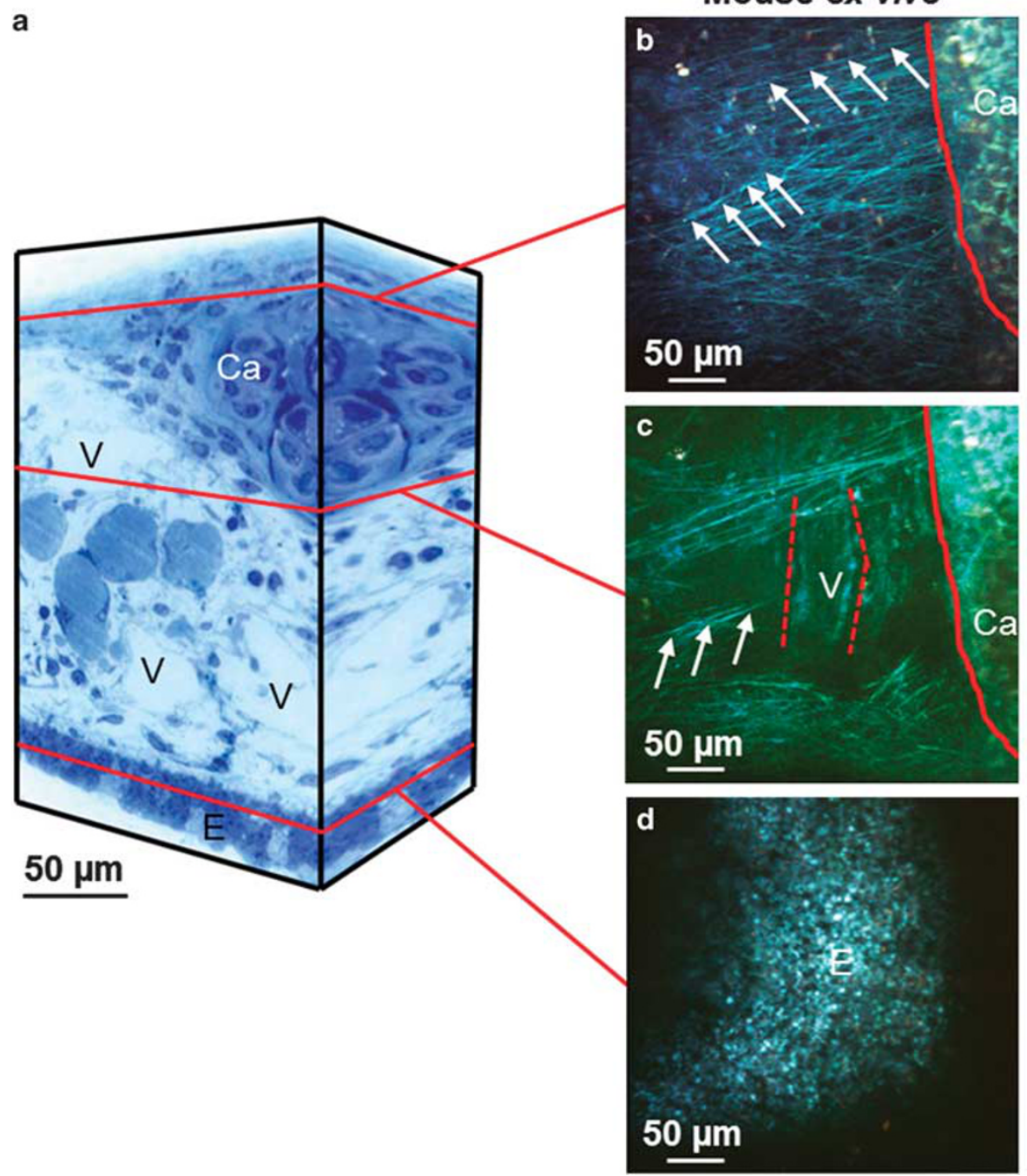

Multi-photon microscopy en face
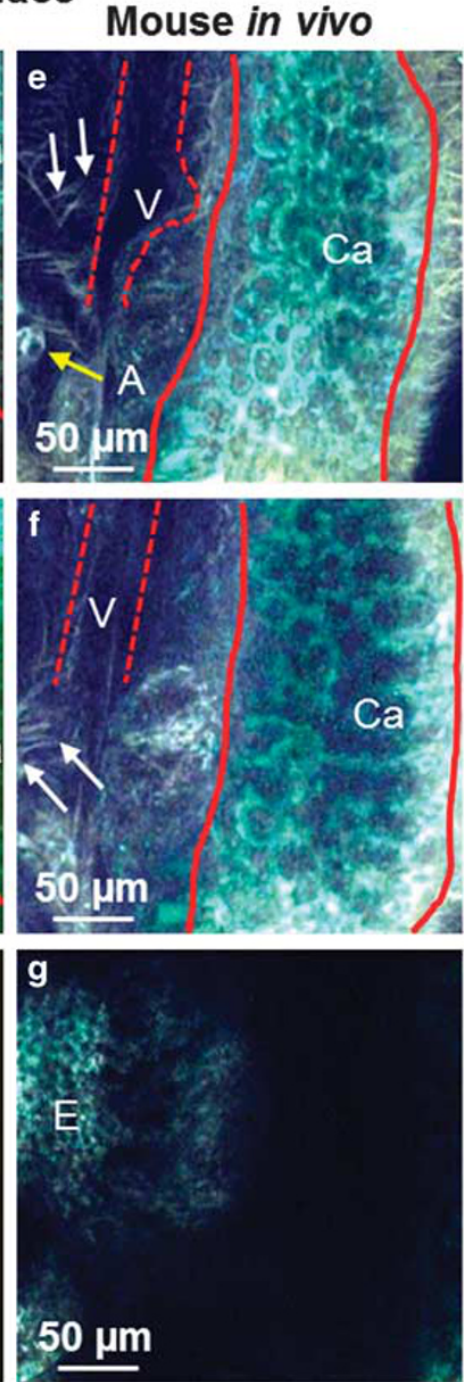

Figure 1 Comparison of imaging murine trachea ex vivo and in vivo by multiphoton microscopy. (a) Three-dimensional (3D) scheme representing a tissue block from the murine trachea. To illustrate the structures visible by conventional microscopy, the image of a semithin section of the murine trachea stained with methylene blue-azure II is shown on the front of the tissue block and the same image was mirrored on the side. Red lines indicate the approximate depth where en face multiphoton images are shown. (b-d) Multiphoton images from a z-stack recorded from a murine trachea ex vivo. $(\mathbf{e}-\mathbf{g})$ Multiphoton images from a z-stack recorded from a murine trachea in vivo. (b and $\mathbf{e})$ Outermost layer of the tracheal wall with fibers of the connective tissue (white arrows), cartilage (Ca, borders marked by red lines), vessel ( $\mathrm{V}$, borders marked by dashed red lines) and adipocytes ( $\mathrm{A}$, yellow arrow). (c and $\mathbf{f}$ ) Tissue in the middle part of the tracheal wall with cartilage (Ca, borders marked by red lines), fibers of the connective tissue (white arrows) and vessels (V, borders marked by dashed red lines). (d and $\mathbf{g}$ ) Section through the epithelial layer (E). For complete z-stacks see Supplementary Movie 1.

reader is referred to the Supplementary Movies for further illustration.

\section{Visualization of Detailed Airway Structures in the Murine Trachea}

In the explanted mouse trachea, we were able to visualize the airway wall in full thickness by taking advantage of its autofluorescence characteristics. Compared with classical histological staining (Figure 1a), structures with similar morphology of cartilage, fibers of the connective tissue, vessels, and epithelial cells were distinguishable by autofluorescence (Figures 1b-d and Supplementary Movie 1). Using intravital imaging of the murine trachea, we observed the same structures albeit with slightly reduced image quality due to motion artifacts (Figures 1e-g and Supplementary Movie 1). To ensure that the trachea was perfused, we injected retroorbitally TRITC-labeled dextran. We could observe a flow of non-labeled erythrocytes in the labeled 

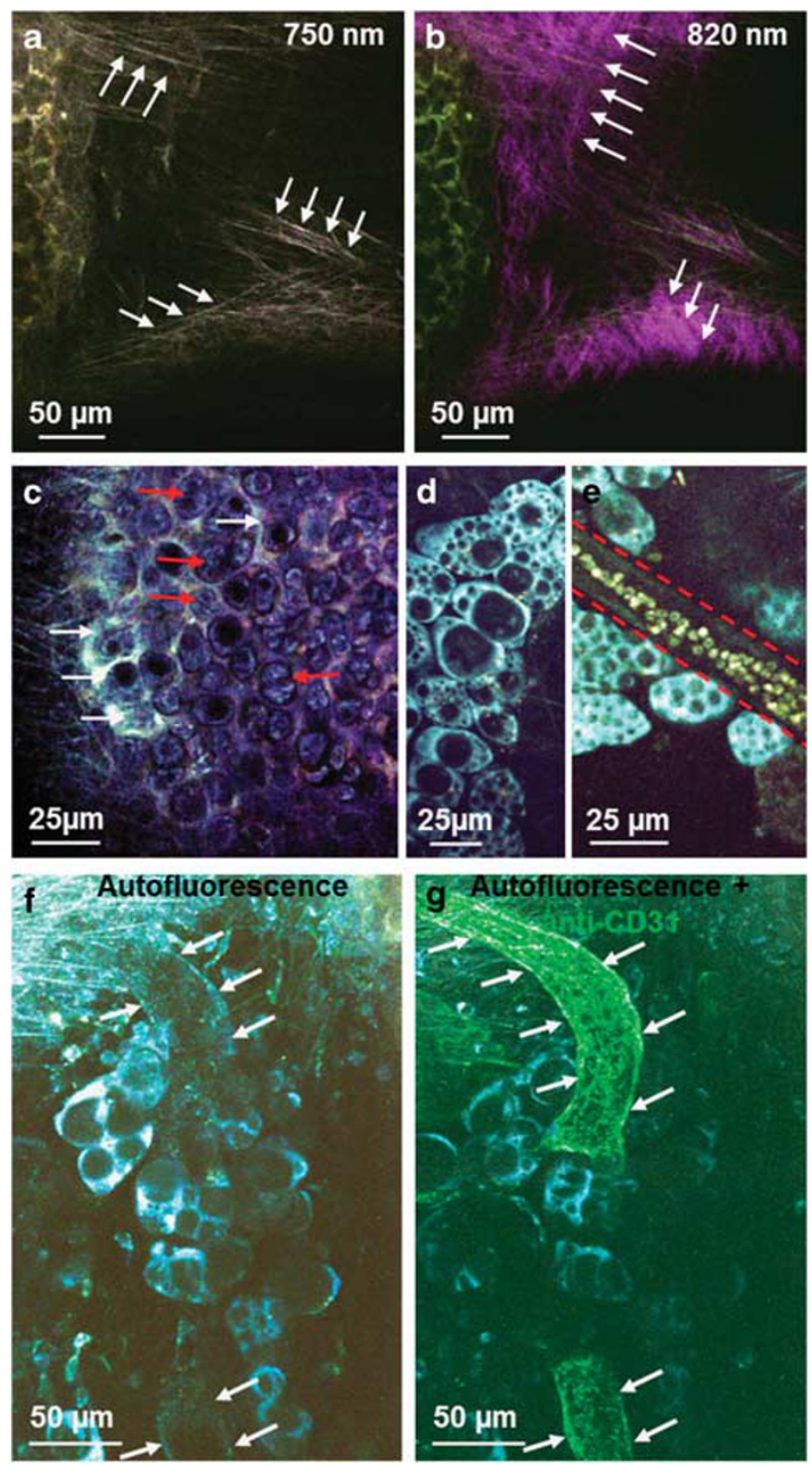

Figure 2 Detailed morphology of the murine trachea ex vivo visualized by multiphoton microscopy. (a and $\mathbf{b}$ ) Two types of fibers could be differentiated by using different excitation wavelengths. Elastic fibers were autofluorescent at an excitation wavelength of $750 \mathrm{~nm}$ (arrows in a), whereas collagen fibers exhibited second-harmonic generation signal at an excitation wavelength of $820 \mathrm{~nm}$ (arrows in b). (c) Detailed morphology of cartilage with chondrocytes (red arrows) and interterritorial matrix (white arrows). (d) Adipocytes could be identified by their non-fluorescent lipid droplets of various sizes in the brightly fluorescent cytoplasm. (e) Blood vessels could be identified by their weakly autofluorescent vessel wall (marked by dashed red line) with brightly fluorescent erythrocytes. (f and $\mathbf{g}$ ) Blood vessels could be detected by a weak autofluorescence signal of the vessel wall (f, white arrows) and the same structure could be labeled by CD31 staining (g, white arrows).

blood plasma through arterioles and capillaries of the trachea (Supplementary Movie 2). In the area between the cartilage rings, connective tissue with two different types of fibers was detected based on the excitation wavelength. Signal from one type of fiber was detected between 400 and $580 \mathrm{~nm}$, mainly by exciting with $750 \mathrm{~nm}$ (Figure 2a). These fibers had a diameter of $\sim 1 \mu \mathrm{m}$ and built a scattered network typical for elastic fibers (cf. Supplementary Table 1). Using an excitation wavelength of $820 \mathrm{~nm}$, the elastic fibers were still slightly visible but an additional fiber type was detected in the $400-440 \mathrm{~nm}$ channel (Figure 2b). Those fibers were $\sim 2.5 \mu \mathrm{m}$ in diameter and had morphological characteristics of collagen fibers (cf. Supplementary Table 1). The tracheal cartilage could be identified by the typical structure of round, clustered chondrocytes with a bright autofluorescent ring (Figure 2c). Using the excitation wavelength of $750 \mathrm{~nm}$, the cartilage was characterized by different emission wavelengths of the collagen matrix and the chondrocytes.

Adipocytes were visible by their bright fluorescent ring corresponding to $\mathrm{NAD}(\mathrm{P}) \mathrm{H}$ autofluorescence (cf. Supplementary Table 1) around the non-fluorescent lipid droplets scattered throughout the bright autofluorescent cytoplasm (Figures 2d and e).

Further structures visible in the connective tissue were vessels, often surrounded by adipocytes (Figure 2e). Increased laser exposure induced fluorescent signal in erythrocytes that was detectable in the $495-550 \mathrm{~nm}$ channel, confirming that these structures are indeed blood vessels (Figure 2e). Without induction of fluorescence in erythrocytes, the identity of blood vessels could be confirmed using anti-CD31 antibodies after recording of the autofluorescent signal (Figures $2 \mathrm{f}$ and $\mathrm{g}$ ). In contrast, the endothelium of lymph vessels was not visible. Reliable detection of lymph vessels was possible by antibody staining in the live tissue with a directly labeled antibody to CD90.2/Thy- $1.2^{19}$ (Supplementary Figures 2a and b).

In the focal plane of the airway epithelium a strong autofluorescence signal in the range of $400-550 \mathrm{~nm}$ corresponding to $\mathrm{NAD}(\mathrm{P}) \mathrm{H}$ autofluorescence (cf. Supplementary Table 1) was detected. To verify that this signal derives from airway epithelial cells, we confirmed the presence of ciliated cells and cilia-driven particle transport with techniques previously reported ${ }^{20}$ and compared the images derived from transmitted light microscopy with the autofluorescent signal (Supplementary Figure 3 and Supplementary Movie 3). In some epithelial cells, red shifted fluorescence signals were detectable in the channel $495-650 \mathrm{~nm}$, most likely corresponding to autofluorescent signals from lipopigments or flavins (cf. Supplementary Table 1 and Figure 3a). Nuclei showed almost no autofluorescence (Figure 3a).

\section{Following Different Cell Dynamics in the Tracheal Tissue}

By capturing autofluorescence images of the same area over a period of 15-40 min, it was possible to observe movement of cells in the trachea without exogenous dyes. The movement of intraepithelial cells was detected as moving dark structures, which moved between the brightly autofluorescent epithelium (Figures 3b-i and Supplementary Movie 4). A similar behavior of intraepithelial lymphocytes has previously been described in the gut epithelium. ${ }^{13}$ 

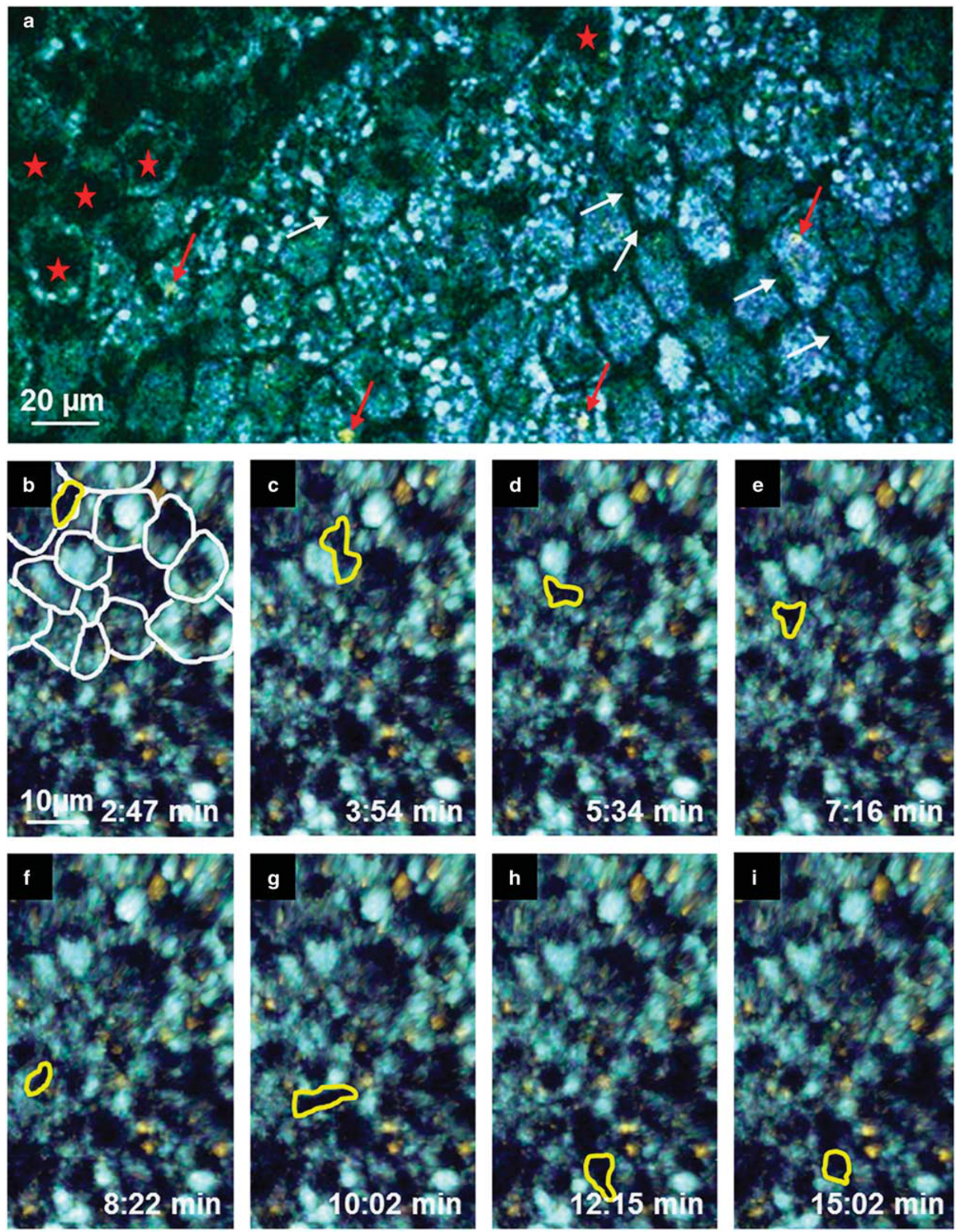

Figure 3 For caption see page on 924. 
In the connective tissue, moving cells were visible by their bright autofluorescent cytoplasm, which emitted light in the range of $440-550 \mathrm{~nm}$ (Figure 4). These cells exhibited different motion patterns. Some cells moved without obvious direction through the tissue and changed their shape during their motion from round to oval or elongated (Figures $4 \mathrm{a}-\mathrm{d}$ and Supplementary Movie 5). Contacts between motile cells were transient (Supplementary Movies 5 and 6). In addition to those short contacts between motile cells, moving cells also interacted with stationary cells where the motile cells moved around the surface of a stationary cell (Supplementary Movie 7). In rare cases, phagocytosis of cells could be observed (Supplementary Movie 8). We could detect also moving cells by autofluorescence in the trachea of living mice (Supplementary Movie 9).

\section{Detection of Laser-Induced Damage}

To determine the effects of laser-induced damage on the behavior of cells in the tissue, we examined the effects of intense laser irradiation to the airway epithelium. Irradiation
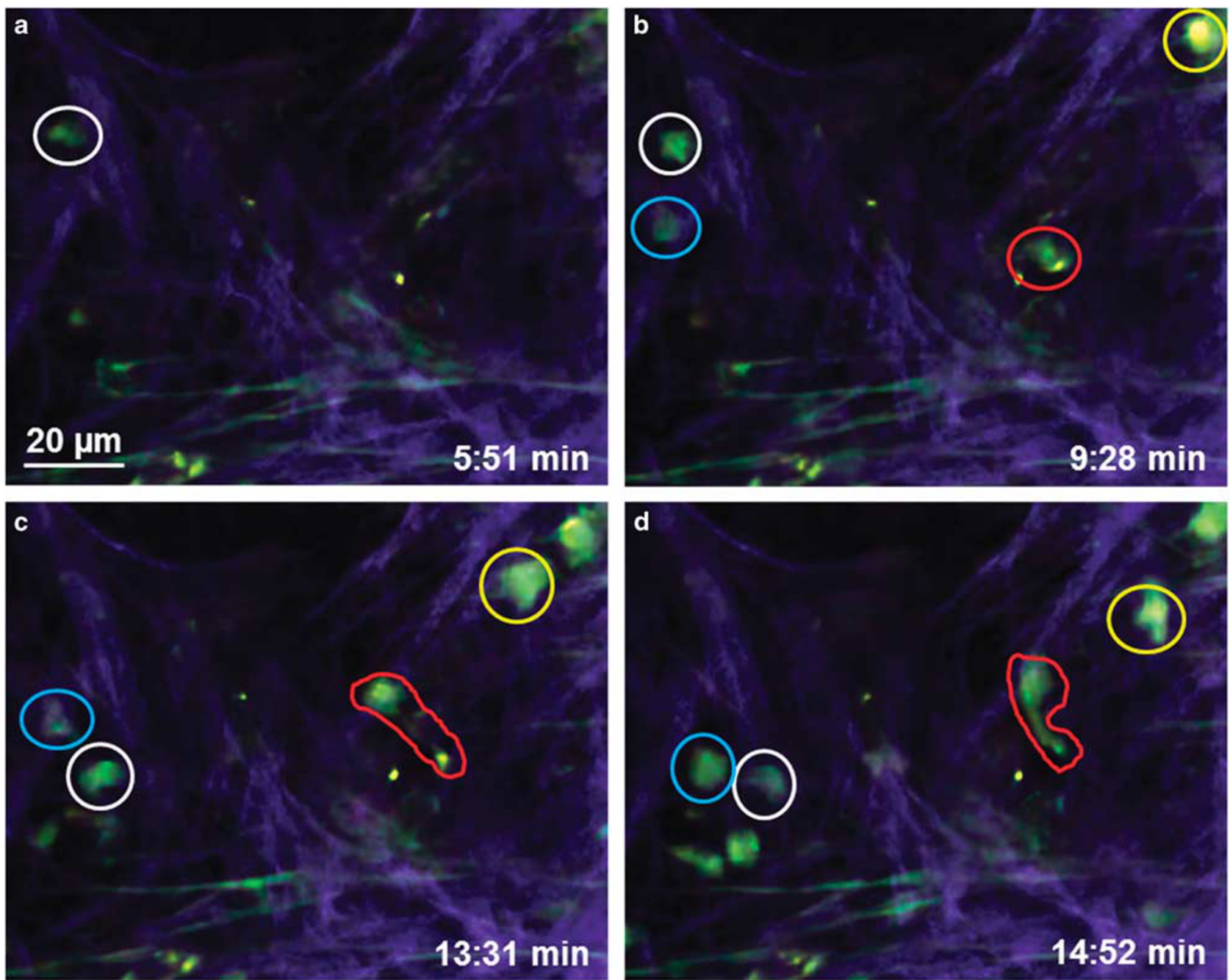

Figure 4 Cell dynamics in the connective tissue of the trachea. (a-d) Time series of a single focal plane showing cells moving through the connective tissue. Motile cells (appearing green) move through the connective tissue. Collagen fibers (purple) and elastic fibers (green) are visible. Four cells are labeled by differently colored circles throughout to facilitate identification (see Supplementary Movie 5).

Figure 3 Cell dynamics in the tracheal epithelium. En face view of the epithelium. (a) Epithelial cells were identifiable by autofluorescence singal surrounding a non-fluorescent nucleus (red asterisks). The borders between the cells were non-fluorescent (white arrows). In some cells, a red shifted autofluorescence signal (red arrows) was observed. (b-i) The Image series shows a non-fluorescent motile cell (framed by a yellow line) moving through the basal part of the epithelium (part of the epithelial cells were surrounded by white lines) by pushing epithelial cells to the side (see Supplementary Movie 4). 


\section{Control}

Inflammation

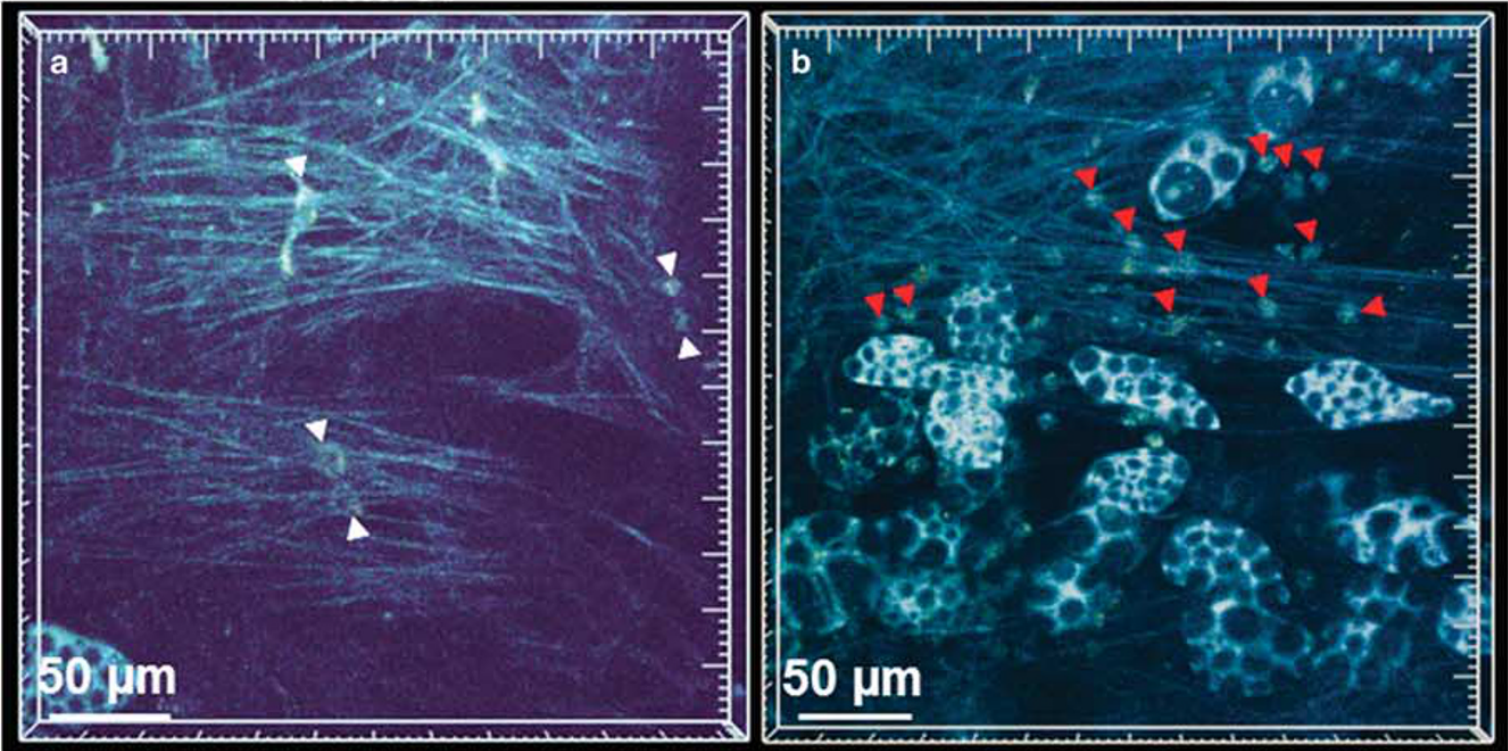

\section{Inflammation}
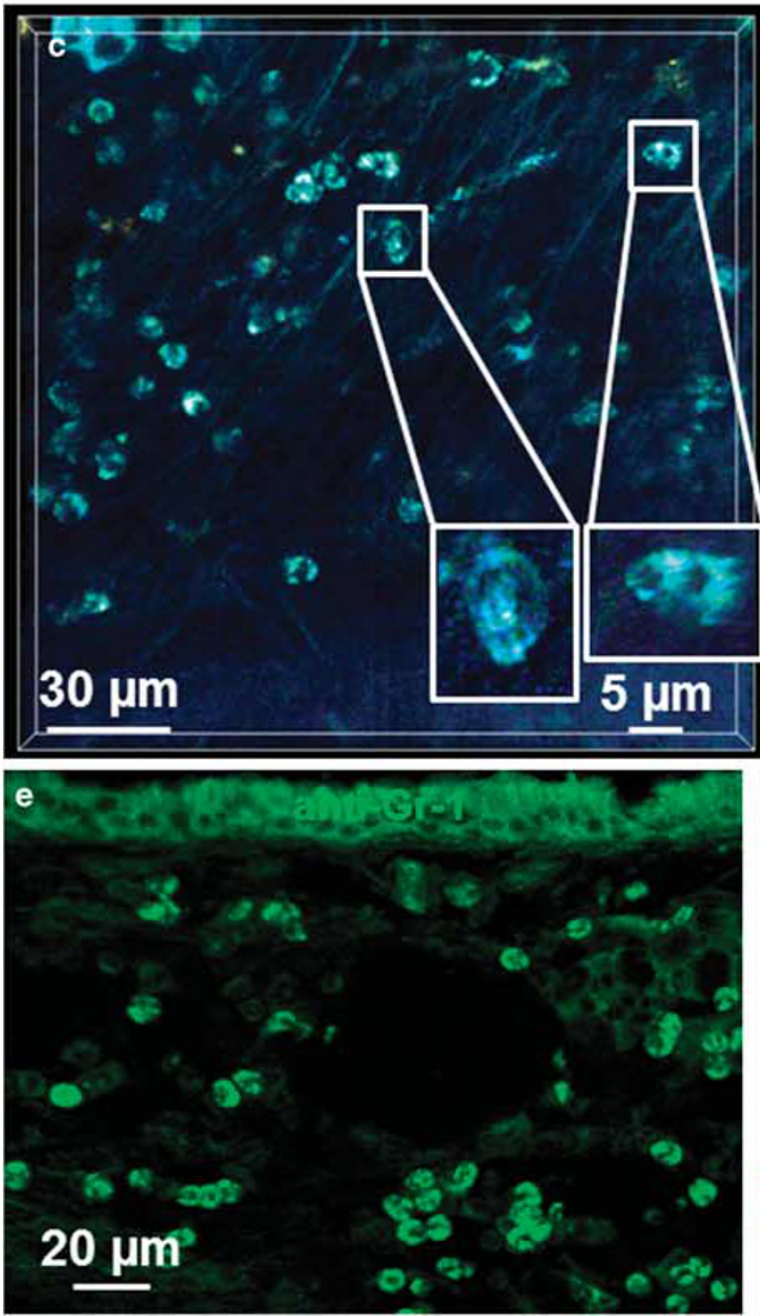

CCR3: Eosinophils Gr-1: Neutrophils
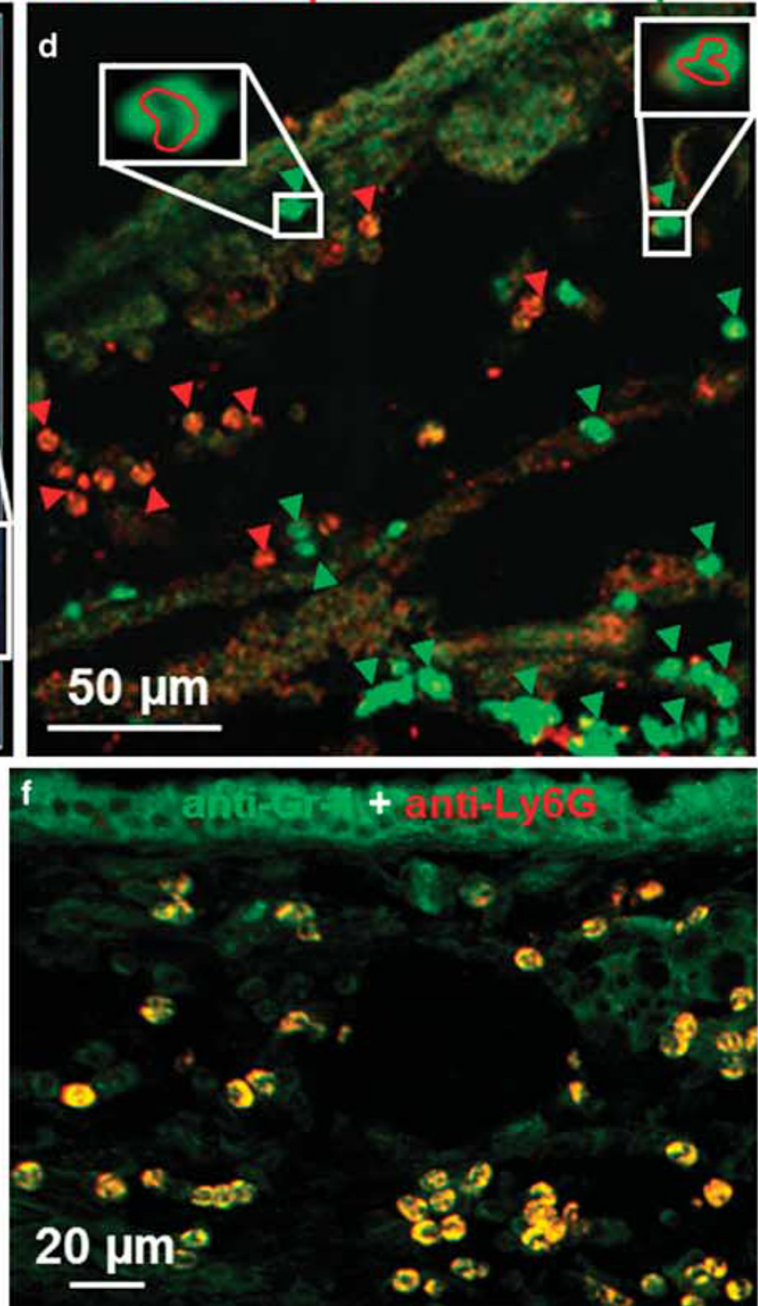
with high laser power at a single position $(750 \mathrm{~nm}, 80 \mathrm{~mW}$ for $8 \mathrm{~s}$ ) induced local hyperfluorescence. Uptake of propidium iodide was confined to cells immediately adjacent to the laserinduced damage (Supplementary Figure 4). Laser-induced hyperfluorescence could also be induced in the connective tissue (Supplementary Figure 5). Occurrence of hyperfluorescence induced cell migration towards the damaged area (Supplementary Movie 10).
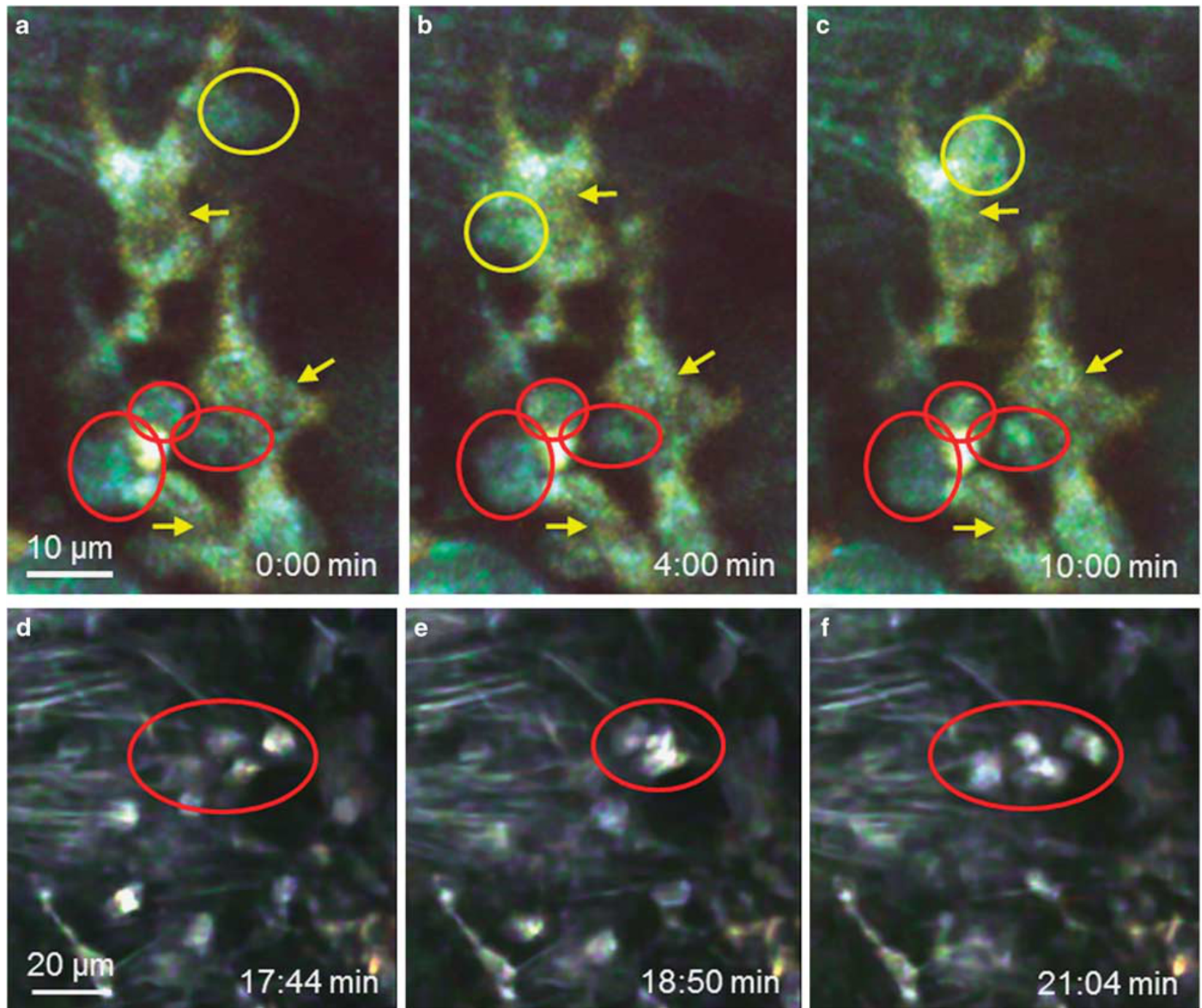

Figure 6 Dynamics of granulocytes and antigen-uptaking cells during an acute airway inflammation. (a-c) Time series of a projection of four focal planes. Contacts between granulocytes (red and yellow circles) and antigen-uptaking cells (stained with DQ OVA, yellow and yellow arrows) could be observed (Supplementary Movie 12). (d-f) Time series of a projection of eight focal planes. Contacts between two or more granulocytes (Supplementary Movie 13). (g) Quantification of the duration of contacts between granulocytes and antigen-uptaking cells (DQ OVA ${ }^{+}$cell-Gr) or between granulocytes $(\mathrm{Gr}-\mathrm{Gr})$, significance was tested with Mann-Whitney U-test. (h-k) Antigen-uptaking cells (stained with DQ OVA, yellow in (h-i) and red in (j and $\mathbf{k})$ ) were contacted by neutrophils (Gr-1-immunoreactive, red circle, yellow in (h and $\mathbf{i})$ and not stained in ( $\mathbf{j}$ and $\mathbf{k})$ ) and eosinophils (Gr-1-negative, white circles).

Figure 5 Inflammatory cells in airway inflammation visualized by multiphoton microscopy. (a and $\mathbf{b}$ ) Time series of a projection of 10 focal planes (a) and 9 focal planes (b). (a) In the connective trachea of control animals, very few cells were observed (white arrowheads (Supplementary Movie 11). (b) During an acute airway inflammation, a large number of motile cells were visible (red arrowheads; see also Supplementary Movie 11). (c) These cells showed a typical morphology with a lobed nucleus (see inset with magnification of boxed area in c). (d) Immunohistochemical staining of a cryostat section from a specimen previously examined by multiphoton microscopy identified these cells as CCR3-immunoreactive eosinophils (red, red arrowheads) and GR-1-immunoreactive neutrophils (green, green arrowheads). (e and f) Double labeling with anti-GR-1 antibody (green) and anti-Ly6G antibody (red) confirmed that GR-1 staining identifies neutrophils (appearing yellow in f). 
g

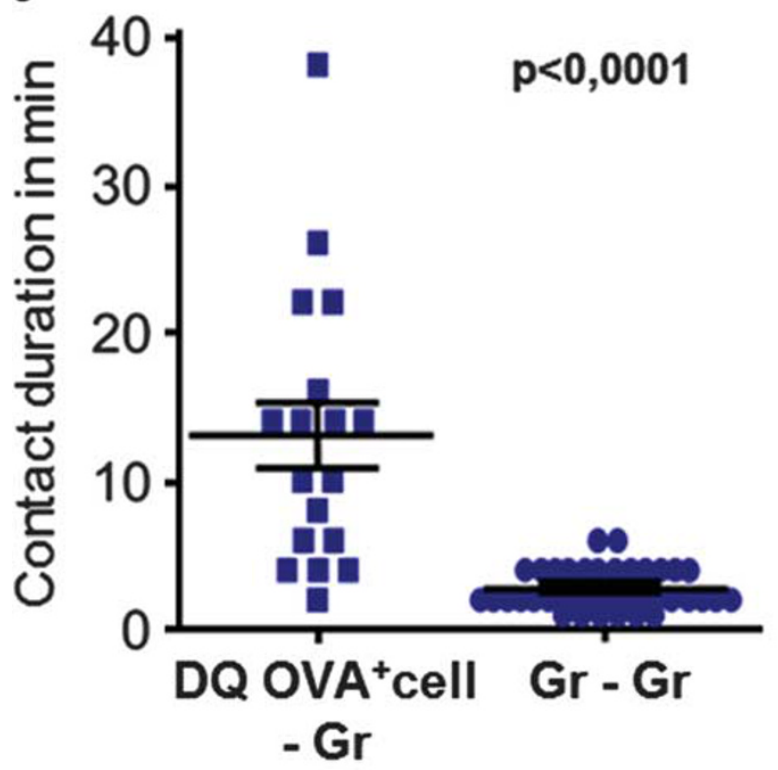

$400-680 \mathrm{~nm}$
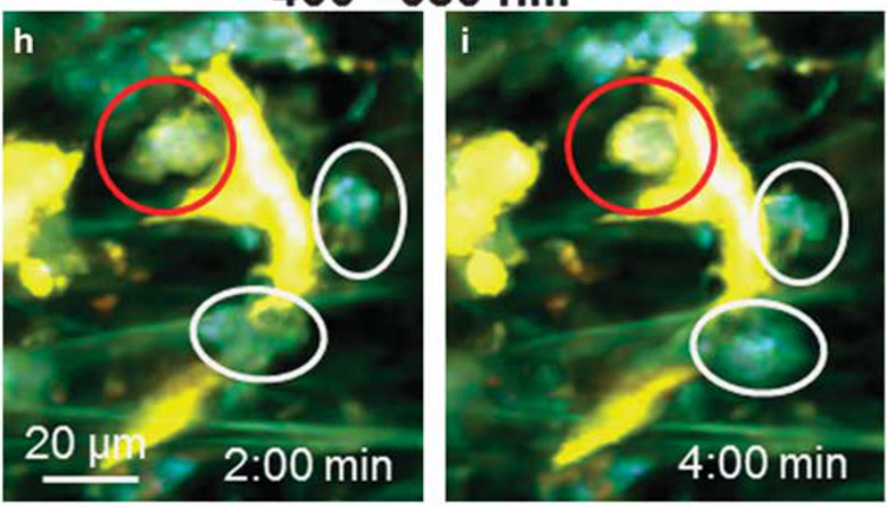

$560-680 \mathrm{~nm}$
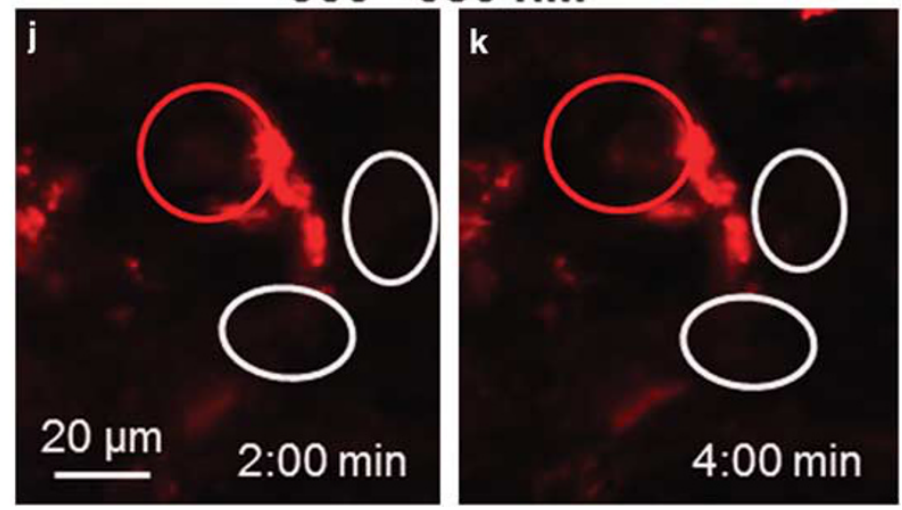

Figure 6 Continued.

\section{Detecting Airway Inflammation}

Differentiation of healthy and inflamed tissue was also possible by autofluorescence imaging (Figure 5). In noninflamed tissue of control mice, only a few autofluorescent cells could be observed (Figure 5a and Supplementary Movie 11). In contrast, the tissue of mice with an acute allergic airway inflammation showed increased numbers of actively moving autofluorescent cells (Figure 5b and Supplementary Movie 11). These cells had a uniform morphology with a round cell body and a lobed non-fluorescent nucleus, which is typical for granulocytes (Figure 5c). Subsequent immunohistochemical labeling with anti-Gr-1 and anti-CCR3 antibodies verified the presence of eosinophil and neutrophil granulocytes (Figure 5d). We confirmed the specificity of the Gr-1 antibody to label neutrophils in this context by double labeling of tissue sections with anti-Gr-1 and anti-Ly6G antibodies (Figures $5 \mathrm{e}$ and $\mathrm{f}$ ). Cells with the morphology of adipocytes, with non-fluorescent lipid droplets in the brightly fluorescent cytoplasm, were occasionally observed in the connective tissue of animals with and without airway inflammation.

\section{Contacts Between Immune Cells During Airway Inflammation}

The addition of DQ OVA to the bath solution made antigenuptaking cells visible (Supplementary Figures $6 \mathrm{a}$ and $\mathrm{b}$ and
Supplementary Movie 12). DQ OVA stained cells with a dendritic cell-like morphology in the connective tissue of the trachea (Supplementary Figure 5c). After fixation and subsequent immunostaining, many of these cells also exhibited MHC II staining (Supplementary Figures 6d-f). In animals with an acute allergic airway inflammation, those DQ OVA-stained cells were in close proximity to autofluorescent granulocytes (Supplementary Movie 12).

Granulocytes moved to DQ OVA-stained cells and maintained contact with them for several minutes either by resting directly on their surface or by moving all over the surface of the DQ OVA-labeled cell (Figures $6 \mathrm{a}-\mathrm{c}$ and Supplementary Movie 13). The contact between granulocytes and DQ OVA-stained cells was significantly longer than the contact between two granulocytes (mean contact time 13 vs $2 \mathrm{~min} 41 \mathrm{~s}$; Figures $6 \mathrm{~d}-\mathrm{g}$ and Supplementary Movie 14).

Addition of FITC-labeled anti-Gr-1 antibody to the bath solution distinguished between Gr-1-positive neutrophil granulocytes and Gr-1-negative eosinophil granulocytes in the living tissue. Although FITC and DQ OVA were visible in the $495-560 \mathrm{~nm}$ channel, we were able to discriminate Gr-1 staining and DQ OVA. DQ OVA was also detected in the 560-680 nm channel and we never observed yellow fluorescence derived from DQ OVA accumulation in granulocytes if only DQ OVA was given. 


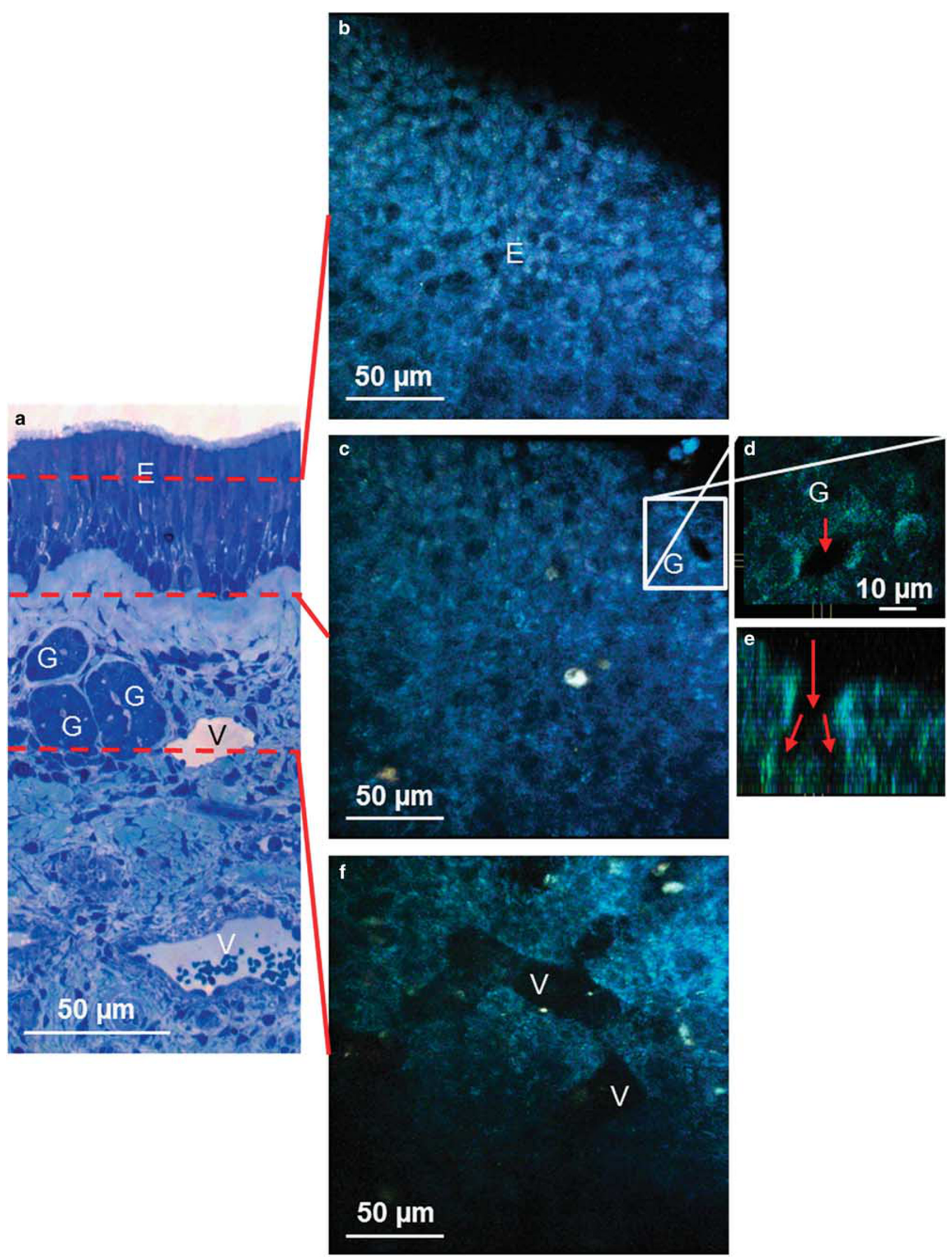




\section{Autofluorescence Imaging of Explanted Human Airway Tissue}

By imaging nasal concha probes from human subjects with autofluorescence multiphoton microscopy, it was possible to visualize structures with the morphology of airway epithelium, glands, and vessels (Figure 7 and Supplementary Movie 15). To demonstrate that the tissue is viable, we induced small lesions in the epithelium and observed the active expulsion of damaged epithelial cells (Supplementary Movie 16).

\section{DISCUSSION}

With autofluorescence imaging, we were able to show airway structures with the morphology of epithelium, blood vessels, connective tissue with their fibers, glands, and cartilage. Without external dyes, we also detected airway inflammation by visualizing increased number of autofluorescent cells with granulocyte morphology. Static multiphoton imaging of lung tissue has previously being used to derive morphologic information such as visualization of cells and different types of fibers without external staining. ${ }^{21,22}$ In our approach, timelapse imaging allowed detecting cell movement, cell-cell interactions and phagocytosis. Additionally, using external dyes, we were able to further characterize tissue structures such as blood and lymph vessels, determine antigen uptake, and could identify eosinophil and neutrophil granulocytes that interact with antigen-uptaking cells.

The importance of visualizing immune cell dynamics to understand immunological processes has previously been demonstrated, ${ }^{23}$ and other studies in the gut and eye have shown that using autofluorescence imaging is a feasible approach to visualize immune cell dynamics. ${ }^{13-15}$ Time resolution was sufficient to reliably detect cell movement in and below the airway epithelium in the excised trachea. Our data demonstrate that the method is able to detect cellular interactions. We further examined the behavior of cells after conscious laser-induced damage. These cells showed hyperfluorescence and sometimes rapidly attracted other mobile cells. In our experiments with low laser exposure, we did not see this behavior.

In the trachea from mice with experimental allergic inflammation, we have observed substantial number of cells with granulocyte morphology without staining, and could discriminate eosinophil and neutrophil granulocytes by the addition of labeled Gr-1 antibody. The involvement of both cell types in asthma has long been recognized, and one way to classify asthmatic patients is to define their disease as neutrophilic, eosinophilic, or paucigranular asthma. ${ }^{24,25}$ However, the exact role for these cells remains to be determined. It is assumed that the cells are mainly involved in tissue damage. ${ }^{26-28}$ During our experiments, which lasted for several hours, we did not see direct damage of the epithelium or other tissue structures, but we found that neutrophils and eosinophils interact with antigen-uptaking cells. DQ OVA has been extensively used to identify antigenpresenting cells such as dendritic cells and macrophages. ${ }^{29} \mathrm{We}$ cannot formally prove that the antigen-uptaking cells with dendritic cell morphology are indeed dendritic cells or macrophages. However, many DQ OVA-uptaking cells had a morphology comparable to dendritic cells and macrophages and exhibited MHC II, indicating a role in T-cell activation. Our data is in line with observations that granulocytes can be involved in modulating the adaptive immune response during airway inflammation. Indeed, evidence exists that both cell types can modulate the T-cell effector function by influencing dendritic cells. Jacobsen et al. ${ }^{30}$ showed that eosinophil granulocytes are important for a Th2-driven T-cell response in the effector phase of an allergic airway inflammation. Evidence for a direct role of neutrophils in dendritic cell maturation has previously been described in experimental autoimmune encephalitis. ${ }^{31}$

Ex vivo imaging has the potential limitation that it does not fully represent the situation in vivo. However, explanted airway tissue from animals expressing fluorescence proteins has previously been used to examine immunological processes in the airways. ${ }^{32,33}$ In accordance with the hypothesis that ex vivo tissue is a good representation of the in vivo situation, we were able to detect cell movements, antigen uptake and processing, and cell-cell interactions that indicate that physiological processes occur in our ex vivo preparation. In addition, our experiments have shown that similar signals can also be recorded in living mice by autofluorescence imaging. This demonstrates that, in principle, there is no hurdle to use autofluorescence imaging in the airways in vivo. However, tissue motion and the more demanding imaging situation led to a reduced image quality. With image registration, new long-distance high NA objectives, and active aberration correction, a considerable increase in image quality is expected.

Although we were able to observe tissue morphology and cellular dynamics, the technique has some limitations. Cells and cellular structures are only visible if they contain fluorophores in sufficient concentration. For example, in ciliated epithelial cells, the cilia were not visible by

Figure 7 Imaging of human nasal concha ex vivo using multiphoton microscopy. (a) Semithin section of nasal concha stained with methylene blueazure II. Red dashed lines indicate the approximate depth where the en face multiphoton images were taken. (b) En face view of the autofluorescent epithelium (E). (c) En face view of the connective tissue directly under the epithelium. G, gland. (d) Magnification of boxed area in (c) red arrow labels opening of gland. (e) Cross-section through z-stack showing the bifurcation of the gland. (f) Connective tissue $20 \mu \mathrm{m}$ under the epithelium with vessels (V). For the complete z-stack see Supplementary Movie 15. 
autofluorescence. We could also not visualize all cells by autofluorescence, probably because the autofluorescence signal of cells mainly relies on $\mathrm{NAD}(\mathrm{P}) \mathrm{H}$ and thus is dependent on the metabolism of the cells. ${ }^{34,35}$ The lack of autofluorescence in cells was also observed in the gut where intraepithelilal lymphocytes appeared as dark structures within the gut epithelium most likely due to their paucity of mitochondria-derived $\mathrm{NAD}(\mathrm{P}) \mathrm{H} \cdot{ }^{36}$ In the trachea, antigenuptaking cells in the tissue were not visible by autofluorescence alone. As almost all cells contain $\mathrm{NAD}(\mathrm{P}) \mathrm{H}$, a higher detection sensitivity could increase the number of cells that are visualized without external labels. As we were not able to detect antigen-uptaking cells by autofluorescence in our setup, we functionally labeled them by DQ OVA. This approach allowed us to identify cells that actively take up antigens.

Although autofluorescence did not lead to unequivocal identification of granulocytes by morphology alone, we successfully used fluorochrome-labeled antibodies to distinguish between neutrophil and eosinophil granulocytes in the tissue. This approach was also successful to identify blood and lymph vessels. Advances in sensitivity, spectral imaging, and Fluorescence Lifetime Imaging hold the potential to identify cells without external labeling. ${ }^{15,37}$

Autofluorescence multiphoton microscopy of explanted tissue was also able to image human airway epithelium and detected repair processes after laser-induced wounding of the airway epithelium of the nasal concha. In contrast to the experiments with murine trachea, we did not observe cell movement below the airway epithelium (data not shown).

We attribute this to the fact that transfer of murine tissue to the microscope was considerably faster than the transfer of excised conchae and that the murine trachea is considerably thinner than the nasal concha preparation. However, these factors can be overcome by moving the microscope closer to the operating theater and by refinement of the preparation. In general, we see no problem to detect cellular behavior in excised human airways by ex vivo microscopy. Then, this approach would open up the possibility to directly examine immunological processes in human tissue without the need to extrapolate from animal studies. It should be noted, however, that the access to healthy human tissue is very limited and experimental conditions cannot be controlled in the same way as in animal studies.

Our experiments show that ex vivo autofluorescence imaging is a valuable tool to examine inflammatory mechanisms in the context of tissue morphology without the need for genetic reporters and holds the potential to be adopted to examine the dynamics of immunological processes in human tissue. As autofluorescence imaging can give detailed information of the morphology of airway tissue even without external dyes, an interesting approach is to integrate multiphoton microscopy in endoscopes. ${ }^{38,39}$ This opens up the possibility to examine patients for alterations of the epithelium, the presence of inflammatory cells below the epithelium, and changes in extracellular matrix composition without the necessity for biopsies.

Supplementary Information accompanies the paper on the Laboratory Investigation website (http://www.laboratoryinvestigation.org)

\section{ACKNOWLEDGMENTS}

This study was supported by funding within the German Center for Lung Research DZL (82DZL00102; to PK and GH).

\section{DISCLOSURE/CONFLICT OF INTEREST}

The authors declare no conflict of interest.

1. Bousquet J, Clark TJ, Hurd $S$ et al. GINA guidelines on asthma and beyond. Allergy 2007;62:102-112.

2. Atkinson TP. Is asthma an infectious disease? New evidence. Curr Allergy Asthma Rep 2013;13:702-709.

3. Caruso M, Crisafulli E, Lizzio R et al. Biologic therapy for atopic asthma and beyond. Curr Opin Allergy Clin Immunol 2013;13:677-685.

4. Lambrecht BN, Hammad $\mathrm{H}$. Asthma: the importance of dysregulated barrier immunity. Eur J Immunol 2013;43:3125-3137.

5. Cahalan MD, Parker I, Wei SH et al. Two-photon tissue imaging: seeing the immune system in a fresh light. Nat Rev Immunol 2002;2:872-880.

6. Stutzmann GE, Parker I. Dynamic multiphoton imaging: a live view from cells to systems. Physiology (Bethesda, MD) 2005;20:15-21.

7. Huang S, Heikal AA, Webb WW. Two-photon fluorescence spectroscopy and microscopy of NAD(P)H and flavoprotein. Biophys J 2002;82: 2811-2825.

8. Zipfel WR, Williams RM, Christie R et al. Live tissue intrinsic emission microscopy using multiphoton-excited native fluorescence and second harmonic generation. Proc Natl Acad Sci USA 2003;100:7075-7080.

9. Zipfel WR, Williams RM, Webb WW. Nonlinear magic: multiphoton microscopy in the biosciences. Nat Biotechnol 2003;21:1369-1377.

10. Richards-Kortum R, Sevick-Muraca E. Quantitative optical spectroscopy for tissue diagnosis. Annu Rev Phys Chem 1996;47:555-606.

11. Wagnières GA, Star WM, Wilson BC. In vivo fluorescence spectroscopy and imaging for oncological applications. Photochem Photobiol 1998;68:603-632.

12. Campagnola PJ, Millard AC, Terasaki M et al. Three-dimensional highresolution second-harmonic generation imaging of endogenous structural proteins in biological tissues. Biophys J 2002;82:493-508.

13. Klinger $A$, Orzekowsky-Schroeder R, von Smolinski $D$ et al. Complex morphology and functional dynamics of vital murine intestinal mucosa revealed by autofluorescence 2-photon microscopy. Histochem Cell Biol 2012;137:269-278.

14. Steven $\mathrm{P}$, Rupp J, Hüttmann $\mathrm{G}$ et al. Experimental induction and threedimensional two-photon imaging of conjunctiva-associated lymphoid tissue. Invest Ophthalmol Vis Sci 2008;49:1512-1517.

15. Orzekowsky-Schroeder R, Klinger A, Martensen B et al. In vivo spectral imaging of different cell types in the small intestine by two-photon excited autofluorescence. J Biomed Opt 2011;16:116025.

16. Lee $\mathrm{AM}$, Wang $\mathrm{H}, \mathrm{Yu} \mathrm{Y}$ et al. In vivo video rate multiphoton microscopy imaging of human skin. Opt Lett 2011;36:2865-2867.

17. Hoffmann J, Marsh LM, Pieper $M$ et al. Compartment-specific expression of collagens and their processing enzymes in intrapulmonary arteries of IPAH patients. Am J Physiol Lung Cell Mol Physiol 2015;308:L1002-L1013.

18. Bölke T, Krapf L, Orzekowsky-Schroeder R et al. Data-adaptive imagedenoising for detecting and quantifying nanoparticle entry in mucosal tissues through intravital 2-photon microscopy. Beilstein J Nanotechnol 2014;5:2016-2025.

19. Kretschmer $S$, Dethlefsen I, Hagner-Benes $S$ et al. Visualization of intrapulmonary lymph vessels in healthy and inflamed murine lung using CD90/Thy-1 as a marker. PLoS One 2013;8:e55201.

20. Bermbach S, Weinhold K, Roeder $T$ et al. Mechanisms of cilia-driven transport in the airways in the absence of mucus. Am J Respir Cell Mol Biol 2014;51:56-67.

21. Pavlova I, Hume KR, Yazinski SA et al. Multiphoton microscopy and microspectroscopy for diagnostics of inflammatory and neoplastic lung. J Biomed Opt 2012;17:036014. 
22. Wang CC, Li FC, Wu RJ et al. Differentiation of normal and cancerous lung tissues by multiphoton imaging. J Biomed Opt 2009; 14:044034.

23. Miller MJ, Wei SH, Parker I et al. Two-photon imaging of lymphocyte motility and antigen response in intact lymph node. Science 2002;296: 1869-1873.

24. Fahy JV. Eosinophilic and neutrophilic inflammation in asthma: insights from clinical studies. Proc Am Thorac Soc 2009;6:256-259.

25. Gibson PG. Inflammatory phenotypes in adult asthma: clinical applications. Clin Respir J 2009;3:198-206.

26. Galli SJ, Tsai M, Piliponsky AM. The development of allergic inflammation. Nature 2008;454:445-454.

27. Hogan SP, Koskinen A, Foster PS. Interleukin-5 and eosinophils induce airway damage and bronchial hyperreactivity during allergic airway inflammation in BALB/c mice. Immunol Cell Biol 1997;75:284-288.

28. Venge $P$. The eosinophil and airway remodelling in asthma. Clin Respir J 2010;4:15-19.

29. Wikstrom ME, Stumbles PA. Mouse respiratory tract dendritic cell subsets and the immunological fate of inhaled antigens. Immunol Cell Biol 2007;85:182-188.

30. Jacobsen EA, Zellner KR, Colbert $\mathrm{D}$ et al. Eosinophils regulate dendritic cells and Th2 pulmonary immune responses following allergen provocation. J Immunol 2011;187:6059-6068.

31. Steinbach K, Piedavent M, Bauer $S$ et al. Neutrophils amplify autoimmune central nervous system infiltrates by maturing local APCs. J Immunol 2013;191:4531-4539.

32. Hammad H, Chieppa M, Perros $F$ et al. House dust mite allergen induces asthma via Toll-like receptor 4 triggering of airway structural cells. Nat Med 2009;15:410-416.

33. Veres TZ, Voedisch S, Spies E et al. Spatiotemporal and functional behavior of airway dendritic cells visualized by two-photon microscopy. Am J Pathol 2011;179:603-609.

34. Vishwasrao HD, Heikal AA, Kasischke KA et al. Conformational dependence of intracellular $\mathrm{NADH}$ on metabolic state revealed by associated fluorescence anisotropy. J Biol Chem 2005;280:25119-25126.
35. $\mathrm{Yu} Q$, Heikal AA. Two-photon autofluorescence dynamics imaging reveals sensitivity of intracellular $\mathrm{NADH}$ concentration and conformation to cell physiology at the single-cell level. J Photochem Photobiol B 2009;95:46-57.

36. Klinger A, Krapf L, Orzekowsky-Schroeder R et al. Intravital autofluorescence 2-photon microscopy of murine intestinal mucosa with ultra-broadband femtosecond laser pulse excitation: image quality, photodamage, and inflammation. J Biomed Opt 2015;20:116001.

37. Gehlsen U, Szaszák M, Gebert A et al. Non-invasive multi-dimensional two-photon microscopy enables optical fingerprinting (TPOF) of immune cells. J Biophotonics 2014;8:466-479.

38. Brown CM, Rivera DR, Pavlova I et al. In vivo imaging of unstained tissues using a compact and flexible multiphoton microendoscope. J Biomed Opt 2012;17:040505.

39. Huland DM, Brown CM, Howard SS et al. In vivo imaging of unstained tissues using long gradient index lens multiphoton endoscopic systems. Biomed Opt Express 2012;3:1077-1085.

$(1)(9)$ This work is licensed under a Creative Commons Attribution-NonCommercial-NoDerivs $\quad \mathbf{4 . 0}$

International License. The images or other third party material in this article are included in the article's Creative Commons license, unless indicated otherwise in the credit line; if the material is not included under the Creative Commons license, users will need to obtain permission from the license holder to reproduce the material. To view a copy of this license, visit http://creativecommons.org/licenses/by-ncnd/4.0/

(c) The Author(s) 2016 